\title{
Higher frequency performance of stress-grading systems for HV large rotating machines
}

\author{
R. Hebner ${ }^{1}$, H. El-Kishky ${ }^{2}$, M. Abdel-Salam ${ }^{3}$, and F. Brown ${ }^{2}$ \\ ${ }^{1}$ The Center for Electromechanics, University of Texas at Austin, Austin, TX 78704 \\ 2 The University of Texas at Tyler, 3900 University Blvd., Tyler, TX 75799 \\ ${ }^{3}$ College of Engineering, Assiut University, Assiut 71516, Egypt
}

\begin{abstract}
This paper presents the results of numerical simulation and analysis of the characteristics of stress-grading systems of high voltage rotating machines against frequency. The stress-grading systems are optimally designed to minimize the local electric field enhancement at a discrete number of frequencies. The performance characteristics of each system are then generated and studied within a given frequency range. The potential distribution characteristics as well as the local electric stress, surface resistance, and the power dissipation characteristics are generated and studied against frequency.
\end{abstract}

\section{Introduction}

There has recently been work investigating the behavior of stress grading in stators under fast rise time pulses [1]. This work highlighted the fact that the behavior of the stress grading at these very high frequencies is different from the behavior at $60 \mathrm{~Hz}$. This work addresses an intermediate between the two extremes studied in the earlier paper. This intermediate region is of growing importance as variable speed generators, such as those connected to flywheels [2-4] or directly to gas turbines, become more important.

Rotating machines can operate for short times with excessive heating or surface discharges in the area of the stress grading. The ultimate failure of a stator insulation system, however, can be the result of long exposure to surface discharges due to localized concentration of electric stress. In particular, intensified electric stress in the overhang portion of the high voltage stator winding is of special concern. Breakdown of the gas adjacent to the insulation in the immediate vicinity of the slot exit leads to the development and propagation of discharges over the end-turns [5-8] which in turn results in gradual degradation of the ground-wall insulation. Therefore, the application of stress-grading systems along the end-turn is considered essential for high voltage machines. Proper design, analysis and development of corona suppression systems can significantly reduce the possibility of surface discharge inception and hence, extend the life of the high voltage stator winding.

This paper presents the results of numerical simulation and analysis of the characteristics of stress-grading systems of high voltage rotating machines against frequency. The stress-grading systems are optimally designed to minimize the local electric field enhancement at a discrete number of frequencies. The performance characteristics of each system are then generated and studied within a given frequency range.

\section{Method of Analysis}

In constant-parameter linear networks, all analysis reduces to solving a system of linear differential and/or algebraic equations. The mathematical tools for solving them were fully developed in the past two centuries. The situation is far more complicated with the analysis of nonlinear networks. The very theory of nonlinear differential equations describing the behavior of nonlinear networks has been much less developed.

The proposed model of the end-turn zone consists of lumped-circuit elements of nonlinear series resistances and linear shunt capacitances connected in cascade, i.e. in segments to represent the stress-grading system and the ground-wall insulation, respectively. The method of describing functions is used for the modeling of the nonlinear resistance of the grading system [5].

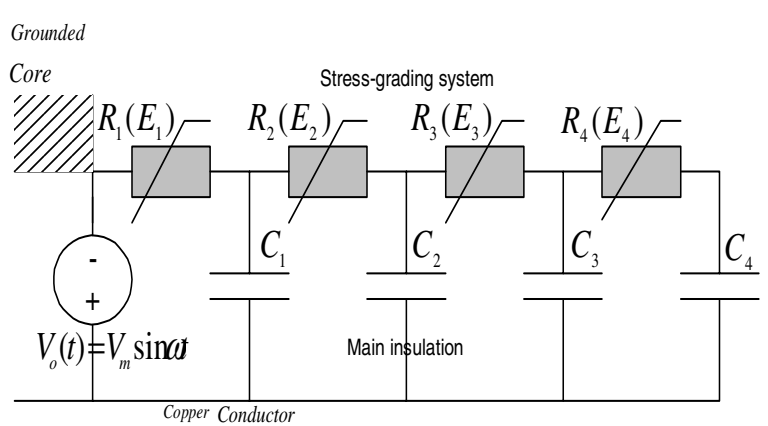

Figure 1: One-dimensional lumped circuit model of the end-turn zone of a high voltage coil. 
The nonlinear characteristic of the SiC-based stress-grading system is approximated by an exponential function of the resistance, the local electric stress, and temperature. The problem is further simplified by dropping the effect of temperature. A set of nonlinear differential equations is then formulated and solved for the optimal design parameters [5].

\section{Results and Discussion}

The set of figures below show the performance characteristics of three different nonlinear resistive stress-grading systems against frequency. A set of stress-grading systems were optimally designed to operate at discrete number of frequencies. The characteristics of these systems are then generated over a wide range of frequencies.

Figures 2-4 show the performance characteristics over a frequency range of $20-300 \mathrm{~Hz}$ of the nonlinear stress-grading system optimally designed at an operating frequency of $60 \mathrm{~Hz}$. The percentage deviation from the desired average field increases with frequency from less than $0.01 \%$ at 60 $\mathrm{Hz}$ to over $100 \%$ at $300 \mathrm{~Hz}$. As the frequency increases, the local surface field increases from its optimal value at $60 \mathrm{~Hz}$ which is virtually equal to the desired average field $(0.45 \mathrm{kV} / \mathrm{cm})$ to a maximum of slightly larger than $0.9 \mathrm{kV} / \mathrm{cm}$ at $300 \mathrm{~Hz}$. Moreover, the power dissipation increases nonlinearly against the frequency. At higher frequencies a high local field of approximately $2.6 \mathrm{kV} / \mathrm{cm}$, or about $600 \%$ of the desired average field is predicted by the model at the slot exit. Figures, 5 and 6 show the performance of the $60 \mathrm{~Hz}$ stress-grading system over a frequency range of $20-1200 \mathrm{~Hz}$.

At higher frequency, the capacitive reactance of the main insulation diminishes, causing the voltages along the stress-grading system to approach the full conductor voltage. This in turn intensifies the local field at the slot exit forcing the resistance of the stress-grading segment at the slot exit to sharply decrease.

Generally, at higher frequency, the effectiveness of the stress-grading system is diminished and its effective length will be limited to the narrow band at the slot exit.

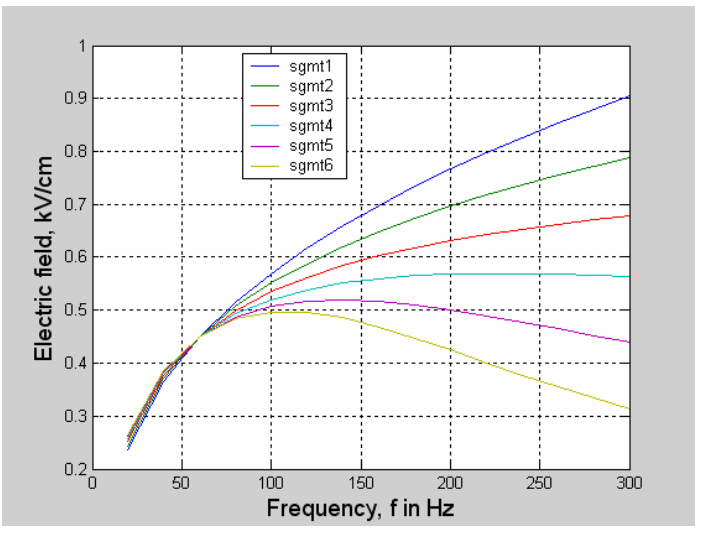

Figure 2: Surface electric field along stress-grading system designed at $60 \mathrm{~Hz}$.

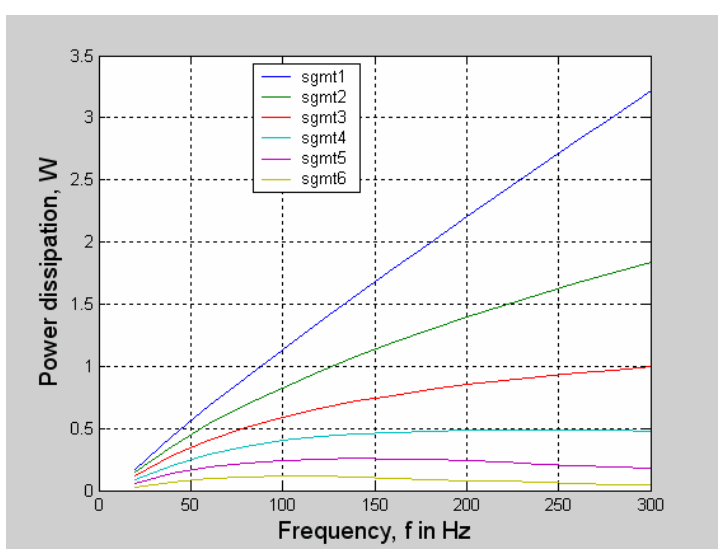

Figure 3: Segment power dissipation along stress-grading system designed at $60 \mathrm{~Hz}$.

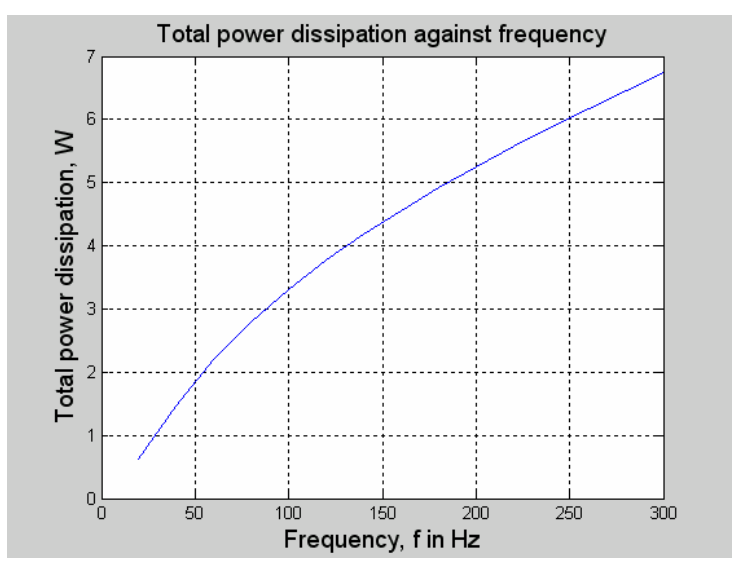

Figure 4: Total power dissipation along stress-grading system designed at $60 \mathrm{~Hz}$. 


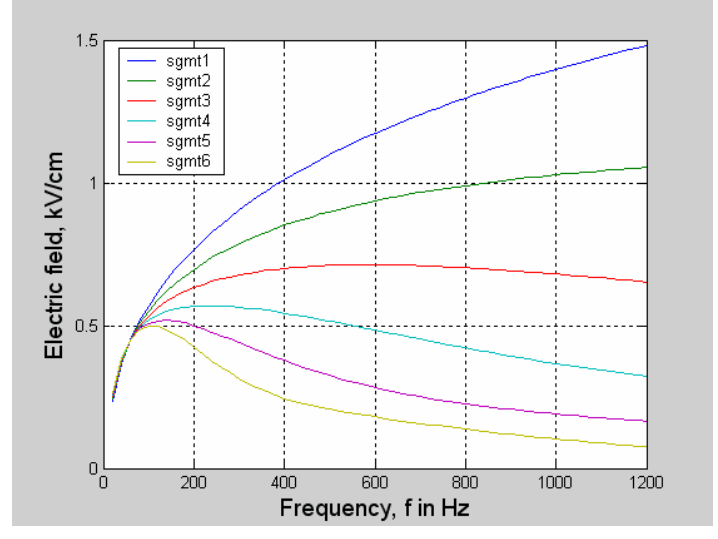

Figure 5: Surface electric field along stress-grading system designed at $60 \mathrm{~Hz}$.

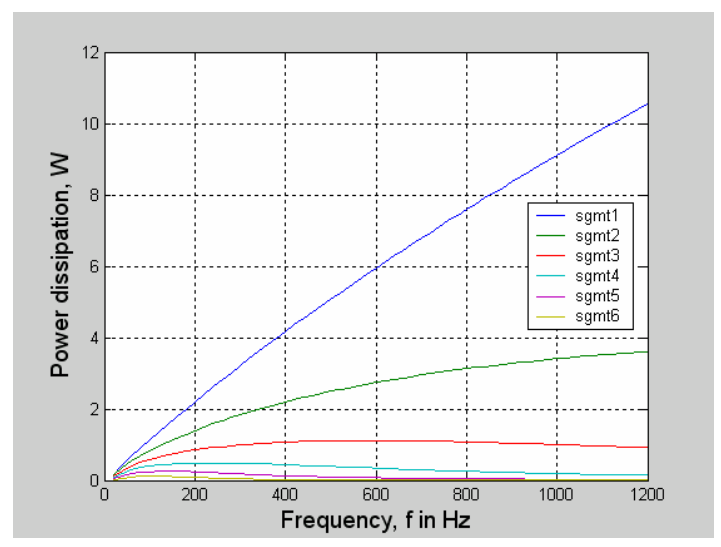

Figure 6: Segment power dissipation along stress-grading system designed at $60 \mathrm{~Hz}$.

The performance characteristics of a $120 \mathrm{~Hz}$ nonlinear stress-grading system over a frequency range of $20-1200 \mathrm{~Hz}$ are shown in Figures 7-12.

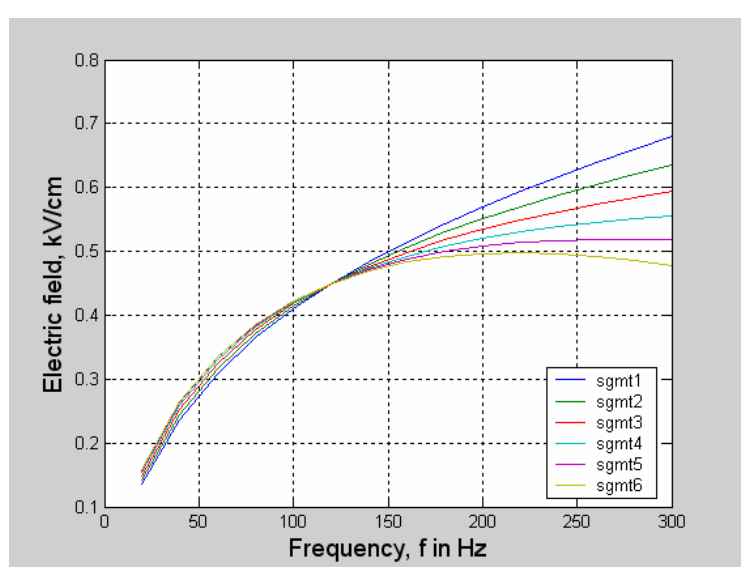

Figure 7: Surface electric field along stress-grading system designed at $120 \mathrm{~Hz}$

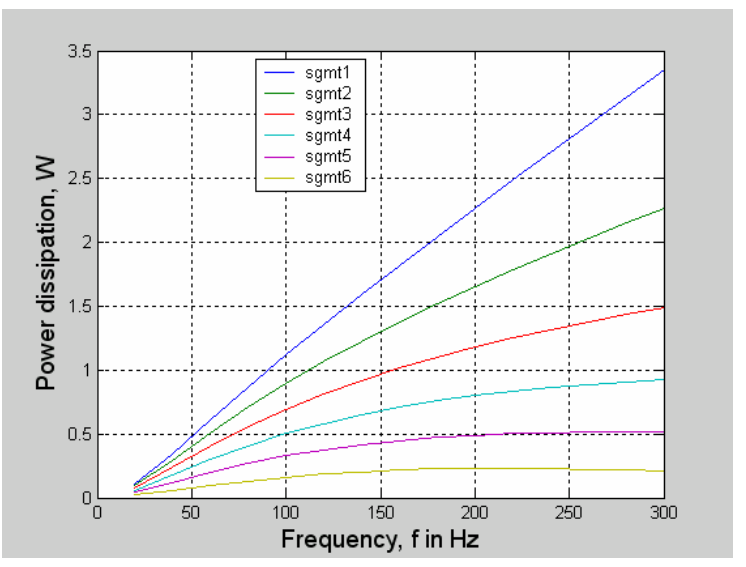

Figure 8: Segment power dissipation along stress-grading system designed at $120 \mathrm{~Hz}$.

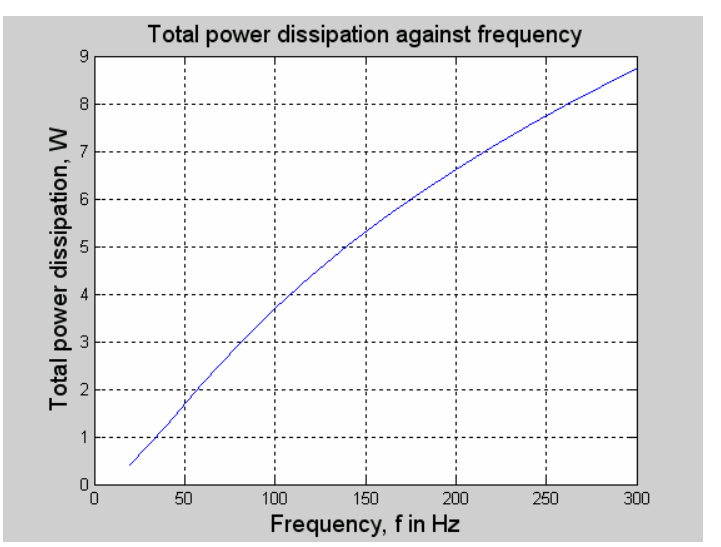

Figure 9: Total power dissipation along stress-grading system designed at $120 \mathrm{~Hz}$.

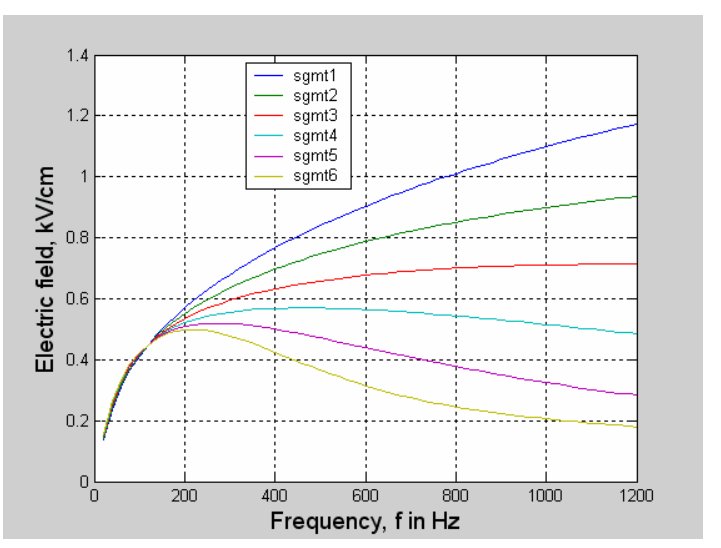

Figure 10: Surface electric field along stress-grading system designed at $120 \mathrm{~Hz}$. 


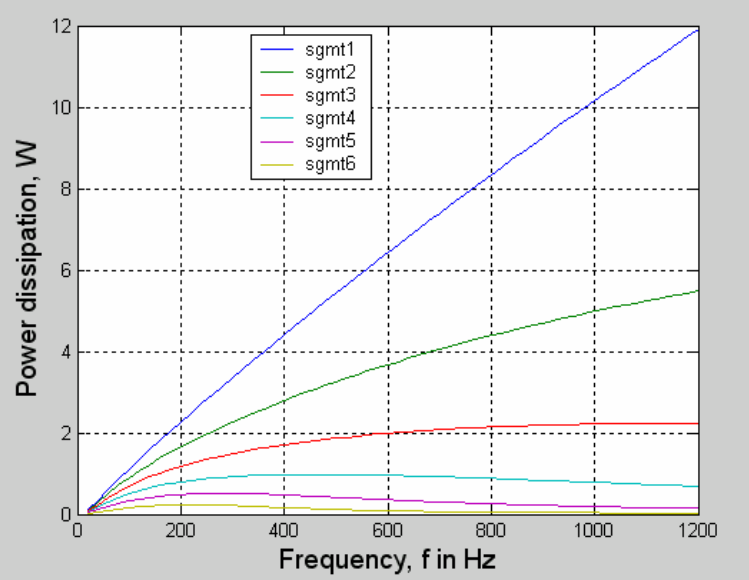

Figure 11: Segment power dissipation along stress-grading system designed at $120 \mathrm{~Hz}$.

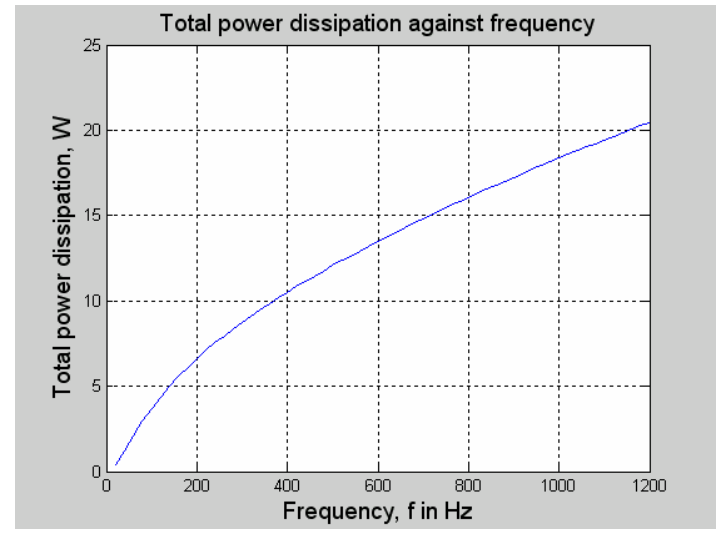

Figure 12: Total power dissipation along stress-grading system designed at $120 \mathrm{~Hz}$.

\section{Conclusions}

At higher frequency, the capacitive reactance of the main insulation diminishes; causing the voltages along the stress-grading system to approach the full conductor voltage. This in turn intensifies the local field at the slot exit forcing the resistance of the stress-grading segment at the slot exit to sharply decrease. Overall, at higher frequency, the effectiveness of the stress-grading system is diminished and its effective length will be limited to the narrow band at the slot exit. The sharp increase of the electric potential along a narrow band of stressgrading system at the immediate vicinity of the slot exit causes drastic concentration of electric field in the area and hence large power loss density. This in turn may lead to severe deterioration of the stressgrading and insulation system.

\section{References}

[1] F. Espino-Cortes, E. Cherney, and S. Jayaram, "Effectiveness of stress grading coatings on form wound stator coil groundwall insulation under fast rise time pulse voltages," IEEE Trans. Energy Conversion, Vol. 20, pp:844-851, 2005.

[2] Heath Hofmann and Seth Sanders, "High-Speed Synchronous Reluctance Machine with Minimized Rotor Losses", IEEE Trans. on IA, Vol. 36, no. 2, 2000.

[3] M. Caprio, V. Lelos, J. Herbst, and J.Upshaw, "Advanced Induction Motor Endring Design Features for High Speed Applications, Proc. IEEE Internat. Elec. Machines and Drives Conf., pp. 993-998, 2005.

[4] M. A. Rahman, A. Chiba, and T. Fukao, "Super High Speed Machines-Summary", IEEE General PES Meeting, June 2004.

[5] H. El-Kishky, R. Hebner, M. Abdel-Salam, and F. Brown, "Minimization of local field enhancement along stress-grading systems of HV large rotating machines", Accepted for presentation at CEIDP 2006, Kansas City, October 2006.

[6] H. El-Kishky, B. Nindra, M. Abdel-Salam, and E. Williams, "Experience With The Development And Evaluation Of CoronaSuppression Systems For High Voltage Rotating Machines," IEEE Trans. on EI, paper no. 36, 2002.

[7] H. El-Kishky, M. Abdel-Salam, H. Wedaa, and Y. Sayed, "Novel techniques for Optimal Design and Analsysis of Stress-grading Systems", Proc. IEEE PES Conference on Transmission and Distribution, Dallas, September, 2003.

[8] J. Rivenc, S. Dinculescu, T. Lebey, "Suitable Properties of Stress Grading Materials", IEE High Voltage Engineering Symposium, August 1999. 